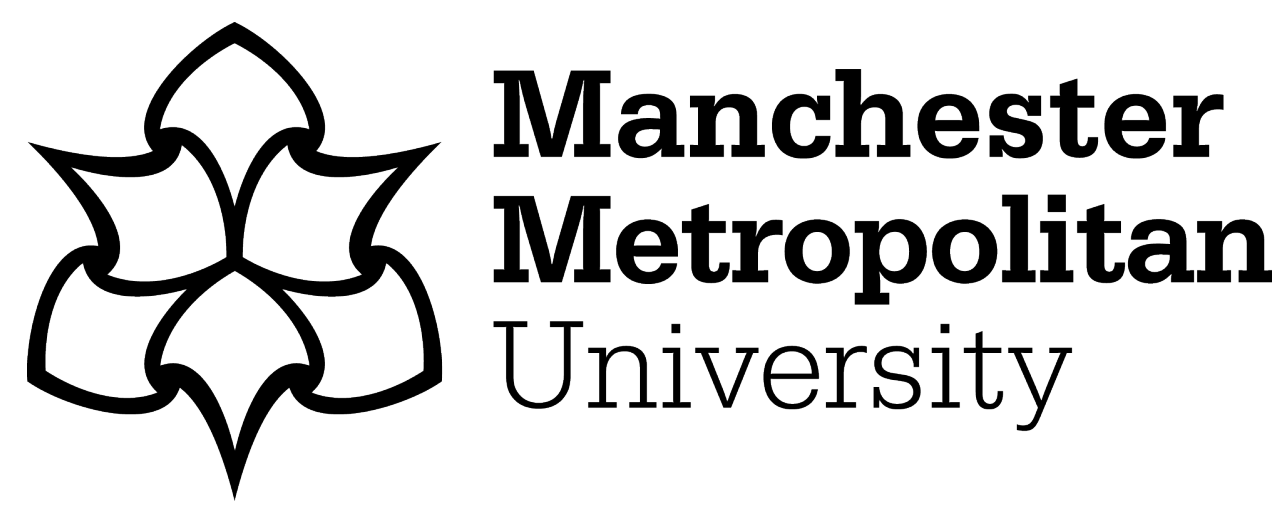

Konovalova, O, Zaporozhets, O, Ohlenforst, B, Peerlings, B, Aalmoes, R, Radulescu, D, Burtea, N, Dragasanu, L, Hooper, P, Heyes, G ORCID logoORCID: https://orcid.org/0000-0002-8073-1975 and Jeram, S (2021) Exemplification case studies as a focus for the implementation of best practices related to aircraft noise management at airports. In: InterNoise21, Washington, D.C., USA.

Downloaded from: https://e-space.mmu.ac.uk/628850/

Version: Accepted Version

DOI: https://doi.org/10.3397/IN-2021-2023

Please cite the published version 


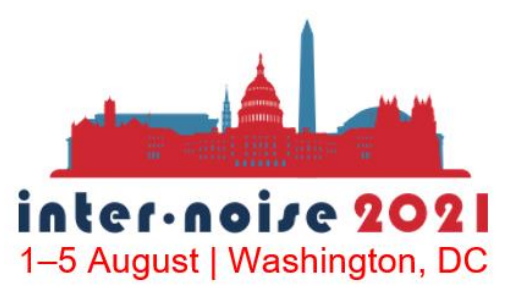

\title{
Exemplification case studies as a focus for the implementation of best practices related to aircraft noise management at airports
}

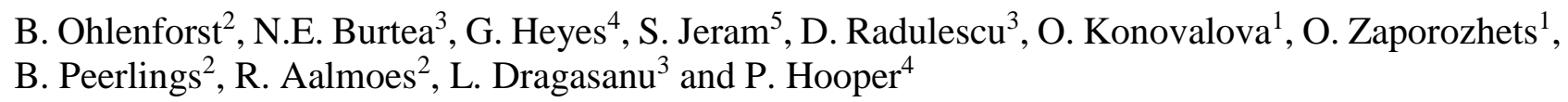

Olena Konovalova and Oleksandr Zaporozhets ${ }^{1}$

National Aviation University

Lubomira Husara av. 1, 03058, Kyiv, Ukraine

Barbara Ohlenforst, Bram Peerlings and Roalt Aalmoes ${ }^{2}$

NLR - Royal Netherlands Aerospace Centre

Anthony Fokkerweg 2, 1059 CM Amsterdam, The Netherlands

Dan Radulescu, Narcisa Burtea and Luminita Dragasanu ${ }^{3}$

COMOTI - National Research and Development Institute for Gas Turbines

220 D Iuliu Maniu Bd., sector 6, cod 061126, OP 76, CP174 Bucharest, Romania

Paul Hooper and Graeme Heyes ${ }^{4}$

Manchester Metropolitan University

E0.04 John Dalton Building, Manchester Campus, Manchester, Great Britain

Sonja Jeram ${ }^{5}$

National Institute of Public Health

Trubarjeva 2, SI-1000 Ljubljana

\begin{abstract}

\footnotetext{
1 ekon@nau.edu.ua, zap@nau.edu.ua

2 barbara.ohlenforst@nlr.nl, bram.peerlings@nlr.nl, roalt.aalmoes@nlr.nl

3 dan.radulescu@ comoti.ro, narcisa.burtea@comoti.ro, luminita.dragasanu@ @ comoti.ro

4 p.d.hooper@mmu.ac.uk, g.heyes@mmu.ac.uk

5 sonja.jeram@nijz.si
}

This study presents the analysis of six airport exemplification case studies undertaken in the European project "Aviation Noise Impact Management through Novel Approaches - ANIMA”. Best practices related to aircraft noise management at airports in individual airport contexts were implemented and evaluated. Case studies on communication and community engagement in airport noise management were investigated at Heathrow (United Kingdom), Ljubljana (Slovenia) and Rotterdam The Hague (The Netherlands) airports. For Zaporizhzhia (Ukraine) and Iasi (Romania) airports, the implementation of interventions related to land-use planning was examined. The interdependencies between noise and emissions were studied for Cluj (Romania) airport. All case studies were performed under the scope of the corresponding national legislation and guidelines. Individual characteristics of airport operations were taken into account. The case studies were 
aligned with expectations and priorities of all involved stakeholders, such as representatives of airport operators, local communities, civil aviation authorities and policy makers. The efficacy of the noise management case studies is assessed in terms of: the capacity to negotiate consensus outcomes, the extent to which noise impact reductions were achieved; and the participants' satisfaction with the process and outcomes. Experience gained from these studies will be used to distill best practices for future interventions.

\section{INTRODUCTION}

From the onset of aviation, communities living in the vicinity of airports have been exposed to aviation noise. The number of people residing inside the $55 \mathrm{~dB} \mathrm{~L}_{\mathrm{den}}$-contour of 47 major European airports was estimated to total 2.58 million in 2017 [1]. Facilitating the estimated long-term growth of aviation $[2,3]$ while reducing noise exposure - the most significant negative impact on residents' quality of life [4] - presents a major challenge. These efforts are complicated by interdependencies between noise and emissions which contribute to climate change and reduced local air quality [3, 5].

Structuring efforts to reduce aviation noise exposure, the ICAO Balanced Approach to Aircraft Noise Management (BA) [6] is a framework for identifying noise problems at airports and for taking measures to reduce these. BA distinguishes between four pillars: 1) reduction of noise at source, 2) land-use planning and management, 3) noise abatement operational procedures, and 4) operating restrictions. In addition to these four pillars, communication, community engagement and stakeholder collaboration are increasingly recognized as relevant factors for effective noise management around airports [7-9].

The ANIMA project aims to address aviation noise impact through novel approaches. Rather than seeking technical solutions, it attempts to identify, develop and assess best practices on noise management at airports, across and beyond aforementioned BA-pillars, thereby taking a social science approach. Based on these best practices, exemplification case study interventions aiming to address challenges in selected airport contexts were implemented and evaluated.

This paper presents the approaches and outcomes of these case studies. Section 2 briefly explains the overall ANIMA approach and the selection and clustering of case studies. For each case study separately, Section 3 describes the background, methods, results and lessons learned. Section 4 discusses overall findings, draws conclusions and lists recommendations.

\section{APPROACH}

Six case studies were conducted between spring 2019 and summer 2021 at airports across Europe, and were clustered in three groups. ANIMA partners developed each case study collaboratively with airports and other local stakeholders to address particular (local) challenges, taking individual airport operations into account. Case studies conducted at Heathrow (United Kingdom), Ljubljana (Slovenia) and Rotterdam The Hague (the Netherlands) airports focused on communication and community engagement; case studies at Zaporizhzhia (Ukraine) and Iasi (Romania) airports dealt with land-use planning; and one case study at Cluj (Romania) airport studied interdependencies between noise and emissions. Airports were selected to include in the study a variety of types, sizes and experience levels with (noise) interventions. All case studies were performed under the scope of the corresponding national legislation and guidelines.

\section{CASE STUDIES}

\subsection{Communication and community engagement}

Case studies investigating interventions related to communication and community engagement were conducted at Heathrow (United Kingdom), Ljubljana (Slovenia), and Rotterdam The Hague (the Netherlands) airports. 


\section{Heathrow Airport and UK Airspace Modernisation (United Kingdom)}

The UK has embarked on a radical process of Airspace Modernisation to optimize the benefits from the adoption of performance-based navigation (PBN) that has been gradually introduced across most airline fleets as newer planes incorporating this technological capability have been purchased. PBN has gradually been replacing ground-based navigation systems with on-board systems incorporating satellite navigational aids with the result that aircraft are able to fly prescribed routes with increased predictability and accuracy. A key benefit of this feature of PBN according to the UK Government [10] is that it concentrates traffic and thus increases airspace capacity, thereby "unlocking" growth, improving safety and offering environmental gains through more direct routing. At the same time the Department for Transport issued Air Navigation Guidance to the UK Civil Aviation Authority (CAA - responsible for overseeing airspace changes), which acknowledged the potential negative environmental impact of changes, and highlighted objectives supporting "a strong and sustainable aviation sector", which are to $[11$, p. 8$]$ :

- Limit and, where possible, reduce the number of people in the UK significantly affected by adverse impacts from aircraft noise;

- Ensure that the aviation sector makes a significant and cost-effective contribution towards reducing global emissions; and minimize local air quality emissions and in particular ensure that the UK complies with its international obligations on air quality.

Thus, from a noise perspective, the CAA and airports responsible for sponsoring airspace change proposals were required to balance the economic and social benefits of a growing air transport industry, and their associated emissions outcomes (i.e. carbon and particulates), with the potential adverse noise impacts on communities near airports. The aim of this case study was to critically reflect on the efficacy of arrangements made by the CAA and airports for arriving at airspace changes which reflect community noise concerns whilst attempting to deliver the wider social and economic benefits derived from aviation.

\section{Method}

Drawing upon UK policy and regulatory documents, the approach to airspace change was captured, highlighting the stepwise process advocated in the Air Navigation Guidance and adopted by the CAA through CAP 1616 [12]. Airport responses to these requirements were critically reviewed by drawing upon published information of the CAA's dedicated Airspace Change portal, and insights into the specific approach followed at Heathrow Airport were garnered from in-depth interviews with key sector actors. Reflections on the efficacy of the community engagement process and the critical issues that should underpin any decisions on airspace changes were extracted from a series of focus groups with amenity group members (mostly those living near Heathrow and Gatwick airports).

Results

Many airports around the UK have undertaken consultation and engagement activities with key stakeholders including community representatives. These have to date largely focused on design principles drawing on design option concepts identified by the CAA [13]. The discussions around design highlight a fundamental challenge around communicating what are quite complex changes with spatially varying implications for noise distribution on the ground. Nevertheless, some consensus has been achieved about the appropriateness of concentration or dispersal of flight tracks for different situations (population distributions). However, there remain some obstacles to communicating the noise exposure associated with specific airspace change proposals associated with:

- Complex overlays of different exposure from linked flight tracks (i.e. use of multiple centerlines to disperse flight tracks) and how best to capture exposure (number and loudness of events?);

- Changing consequence of flight path separation with altitude;

- How to illustrate 'winners' and 'losers' and the lack of consensus/evidence as to whether it is fair (and indeed healthy) to increase the number of people exposed to lower levels of noise in order to decrease the exposure of the most noise-affected;

- The acceptability of increasing aircraft numbers despite the reduction in aircraft noise footprints. 


\section{Lessons learned}

The adoption of PBN requires the management of flight track concentration for different circumstances. Simple materials must be developed to highlight changes in noise exposure on the ground associated with concentration or dispersal, incorporating the number and noisiness of events so that the implications of PBN flight tracks can be communicated and effective stakeholder dialogue can take place. There is a community preference for noise sharing (flight track dispersal) that may run counter to UK/EU policy to limit the number of people significantly affected by aircraft noise. There is a lack of evidence on the potential impacts associated with dispersal/concentration (annoyance response, sleep disturbance, long-term health consequences), and this is a major constraint to effective decision making.

\section{Ljubljana Airport (Slovenia)}

Ljubljana Airport is a small airport with less than 50,000 movements per year. It is located $20 \mathrm{~km}$ northwest of the Ljubljana capital. A single runway is 3,300 $\mathrm{m}$ long. The airport handled more than 1.7 million passengers and approximately 31,000 aircraft operations in 2019. Seven municipalities with 123,696 citizens have to deal with aviation noise. The strategic noise map shows that near 5,000 citizens live under the contours of the noise map with noise indicator $L_{d e n}>37 d B(A)$ and may be affected by aircraft noise [14]. The noise showed to be a problem mainly in the summer evenings, when the limit value $53 \mathrm{~dB}(\mathrm{~A})$ was reached. The greatest agitation, dissatisfaction and distrust among local authorities and communities was caused by the unannounced change of take-off direction over Kranj in 2013. After a long time of complaints, the mayors of the nearest municipalities organized a meeting in 2019 and demanded explanations (Call of Mayors) from local authorities and the abolition of the new take-off route. The mayors also questioned the performance and reliability of the noise measurements. In response, Fraport Slovenija initiated the Airport Environmental Partnership of stakeholders and explained the main issues in a written response. However, communities were not satisfied and demanded more information and further discussions.

\section{Method}

To facilitate the dialogue among all stakeholders including local Authorities and communities, a workshop was organized in December 2019 as part of the ANIMA project [15]. The event took place at the City Municipality of Kranj. In conclusion the ANIMA team suggested setting up a forum, identifying all the stakeholders needed with duties and responsibilities including local communities to allow for an open dialogue relevant to noise and other airport-related environmental issues.

In the near future another discussion is planned, on establishing a transparent information policy that would allow constant access to information and explanations from the responsible authorities and furthermore to solve the existing problems in a constructive dialogue.

\section{Results}

Five presentations including topics on aviation noise and its adverse effects on public health, Collaborative Environmental Management (CEM), noise annoyance and indicators, non-acoustical factors and known best practices for communication and community engagement were presented in the first panel. In the second panel the main stakeholders presented operations at Ljubljana Airport, design of instrument procedures and flight procedures including noise management. Airport noise monitoring and strategic noise maps were presented and local authorities exposed engagement of the municipalities pointed to concerns that citizens have and would like to discuss. Aircraft noise and land-use planning legislation were presented by relevant ministries and Fraport Slovenija [16]. After each panel, a debate took place, involving all the parties present. The main questions asked in the discussion were:

- The role that introducing more legal noise indicators would have on the understanding of noise annoyance and sleep disturbance of people living in surrounding communities;

- The need for evaluating noise with a finer granularity, through specific analysis of events and characteristics, to overcome average noise levels that could be irrelevant for annoyance purpose;

- The way to assess the effectiveness and the real gain of interventions against noise before the start of their implementation process; 
- The dispersion of the flight path and how relevant it would be to concentrate the tracks;

- The need for a more detailed identification of real annoyance of people before establishing new procedures or interventions - in order to make sure to gain public acceptance, and solve the actual problem, rather than present a solution to a non-existing one.

Very informative presentations and discussions are summarized in the workshop proceedings [15]. The report was translated into Slovenian language. All participants were satisfied with the topics presented confirming that presentations were useful and important for them.

\section{Lessons learned}

The ANIMA event showed that prevention and proactivity are key when considering noise management. The level of awareness often differs among stakeholders, hence the importance of working collaboratively towards common noise policy which benefits all parties. With support of ANIMA initiative, a much-needed dialogue around Ljubljana Airport has restarted. A Dialogue Forum should consider the problems in the context of a broader picture including interdependencies (air pollution), land-use planning and quality of life.

\section{Rotterdam The Hague Airport (The Netherlands)}

Rotterdam The Hague Airport (RTHA) is a minor international airport with a single 2,200 m runway. The airport has a Regional Consultation Committee, including stakeholders and community representatives, and project teams can be formed to address specific activities. One such team was formed for the topic of this case study.

This case study investigates the evaluation of an alternative departure procedure aiming to reduce noise annoyance for as many residents as possible and involve communities around RTHA in the decision-making process. The study would evaluate whether the changes in the calculated noise levels would be perceived by representatives of the community and discuss their findings among each other and the project team.

The technical analysis included a quick-scan of changes in noise exposure for the departure route for runway 06 . The results of the investigation showed a $10 \%$ reduction of highly annoyed people in the $56 \mathrm{~dB}(\mathrm{~A}) \mathrm{L}_{\mathrm{den}}$ contour, while there would be a $2 \%$ increase in the lower $40 \mathrm{~dB}(\mathrm{~A}) \mathrm{L}_{\mathrm{den}}$ contour, and a shift from number of people annoyed from the north to the south of the route.

\section{Method}

An online listening test presented participants with simulated audio samples of aircraft noise for the current and alternative departure procedure at five locations, each affected differently by the changed procedure. These are shown in Figure 1, together with the current (gray line) and alternative (blue line) departure procedures. Those participating would not know beforehand the locations that were evaluated or which of the two sounds that were compared was the current or the alternatively departure procedure.

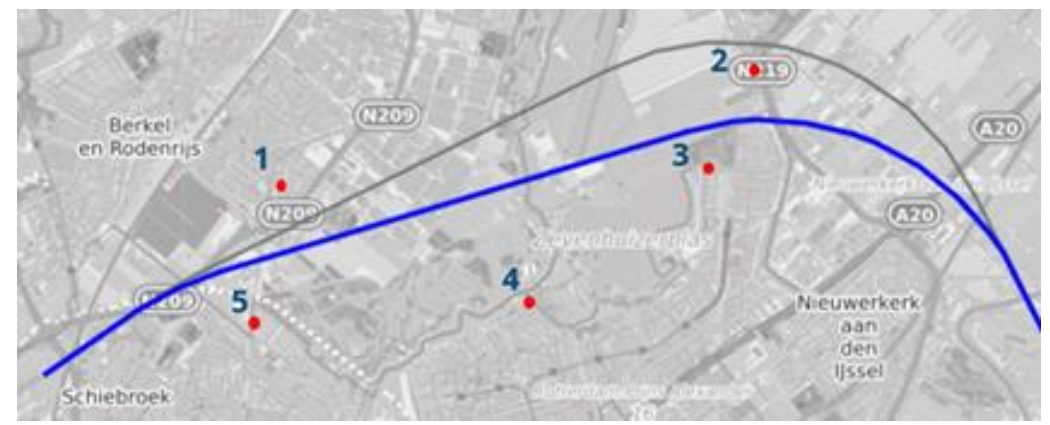

Figure 1: Current (gray) and alternative (blue) departure procedure and the five examined locations for the listening test

Due to COVID-19, the listening test had to be performed at home. Participants listened to the two departure procedures for each of the five locations, and after that, listened to the two procedures at the same time by alternating between them in a 4 second interval. Participants rated the sounds by 7- 
point Likert scale between -3 and +3 . When both routes were perceived equally loud in noise level the rating would be zero. In total, 25 participants provided their subjective evaluation. During information meetings afterwards, technical details related to the two departure procedures were explained, such as the noise levels calculations, technical aspects of the procedures and the listening test setup. The actual locations and which sound (the first or the last) belonged to which departure route was revealed as well. Participants were asked whether they would personally benefit from a possible change in procedure, whether they thought that the overall community would benefit and whether the community engagement strategy was helpful and valued.

\section{Results}

Listening test scores were averaged over all 25 participants. For each of the five locations illustrated

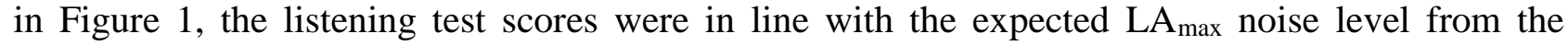
calculations. The calculated changes in noise levels for location $3(4.3 \mathrm{~dB})$ and location $4(4.4 \mathrm{~dB})$ were almost identical. However, the score from the listening test suggests that the higher noise level for location 3 was perceived as more annoying (score 1.8) compared to the increase in noise level for location 4 (score 1.2). It seems that for higher noise levels, a reduction is appreciated more compared to further reduction of a lower noise level.

Mixed results were received for questions about the personal benefit and the overall benefit for the community. Most participants put the overall benefit of the community first and reported that the process, the explanations, the listing test and the meetings were helpful and valued. However, some participants were unhappy about the approach as they felt the noise exposure and the annoyance was only shifted and not reduced.

\section{Lessons learned}

Overall, the participants valued the community engagement procedure to investigate the effects of a possible change in departure procedure. Sharing information as well as the dilemma of the case (i.e., improving the situation for some at the cost of others, or striving for an overall benefit) helped to create understanding and empathy. However, as the aircraft noise is not reduced but rather shifted to a different location, the possibility of sharing exposure and annoyance was present. Especially for this kind of complex case, transparency is very important and essential to create trust and the feeling of fairness.

\subsection{Land-use planning}

Interventions related to land-use planning (LUP) were studied using case studies at Zaporizhzhia (Ukraine) and Iasi (Romania) airports.

\section{Zaporizhzhia Airport (Ukraine)}

Zaporizhzhia International Airport is located $12 \mathrm{~km}$ north-east from the regional city Zaporizhzhia. It is the fifth major airport in Ukraine. Its infrastructure includes one concrete runway 2,500 $\times 42 \mathrm{~m}$ operated in both directions for take-off and from the north for landing.

This case study focuses on implementation of noise protection zones (NPZ) with recommendations on compatible land-use planning and protecting people from noise exposure using efficient dialogue between airport, CAA and local authorities on this problem. In respect to this the procedure of Environmental Impact Assessment (EIA) should be mentioned, especially the timely, adequate and effective EIA informing procedures of the public exposed to aircraft noise and other airport types of the impact. This case study is considered due to its concern for the following aspects:

- Implementation of new legislation. According to the Air Code of Ukraine (2011) and Aviation Rules of Ukraine AR-381-2019, civil airports are obliged to establish NPZ. The NPZ boundaries must be calculated for current and future traffic scenarios and validated by measurements at predefined points at least once every five years.

- Airport development plans. The airport expected a $25 \%$ growth in passenger traffic, prior to COVID-19. 


\section{Method}

According to the national sanitary and hygienic regulations for planning and construction of residential areas two criteria are used as normative for aircraft noise zones - equivalent and maximum noise levels. Noise levels are regulated with respect to restrictions for constructions around civil airports designated the areas as 'Unsuitable for Construction', 'Protection against noise impact' and 'Limitations for residential Construction'.

Where noise exposure is principally composed of a small number of discrete fly-by events, as in regional airports with low flight intensity, equivalent noise level is not representative, especially with

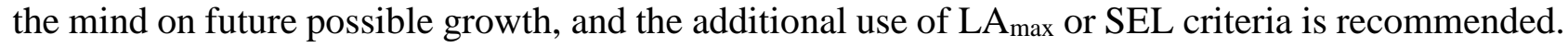
$\mathrm{LA}_{\max }$ can be also used for improving the measures of noise control inside NPZ, e.g. for more efficient sound insulation of the buildings. For strategic noise mapping it is required by Aviation Rules AR381-2019 to use noise indexes such as $\mathrm{L}_{\mathrm{den}}$ and $\mathrm{L}_{\mathrm{dn}}$ also, but there is a need to fully integrate those criteria in Ukrainian legislation for environment and human health protection.

For calculation of noise contours on the basis of analysis of flight plans for the 2019 year the following flight traffic scenarios were elaborated: 1) the maximum intensity of aircraft movements reached in 2019 taking into account distributions between aircraft routes; 2) perspective intensity of aircraft movements equal to maximum operational capacity of the airport runway-apron-terminal system.

\section{Results}

As a result of calculations, noise protection zones are presented on maps (Figures 2 and 3). Different colors indicate normative values of $\mathrm{LA}_{\mathrm{eq}}$ and $\mathrm{LA}_{\max }$, on the left for daytime and on the right for nighttime.
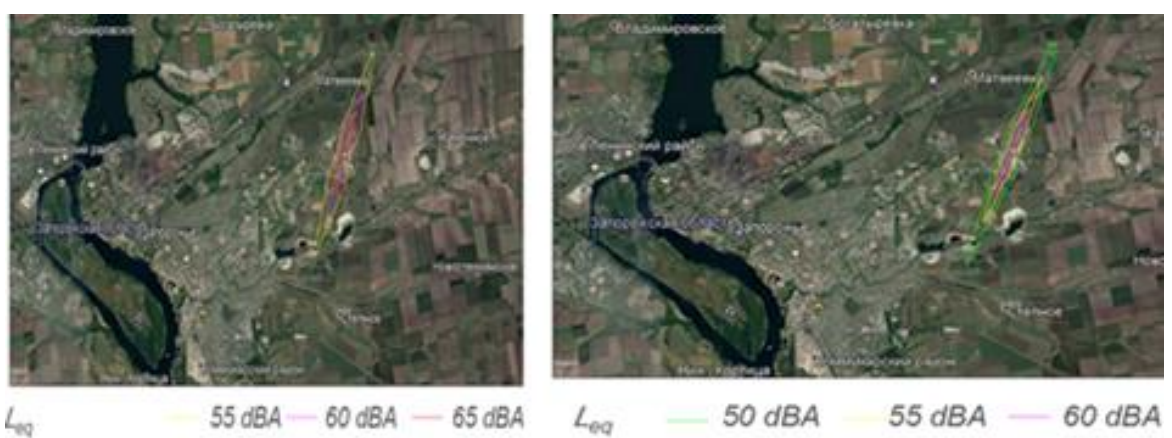

Figure 2: Noise contours ( $\mathrm{LA}_{\mathrm{eq}}, \mathrm{dB}(\mathrm{A})$ ) for Zaporizhzhia International Airport: left - for daytime 7:00-23:00; right - for night-time 23:00-7:00
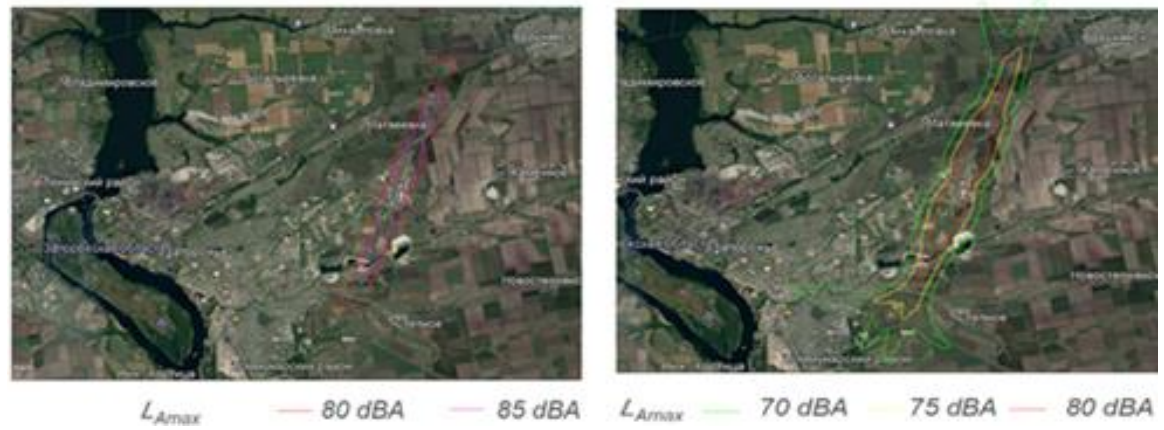

Figure 3: Noise contours $\left(\mathrm{LA}_{\max }, \mathrm{dB}(\mathrm{A})\right.$ ) for Zaporizhzhia International Airport: left - for daytime 7:00-23:00; right - for nighttime 23:00-7:00

The results of noise measurement in the vicinity of Zaporizhzhia airport were analyzed from several points of view, but the main is a comparison with the normative values of environmental noise in accordance with the requirements of national norms and rules.

\section{Lessons learned}

The implementation of ICAO Balanced Approach to noise control in Ukraine is focused on aircraft noise exposure assessment, establishment of NPZ and compatible land-use planning. 
As the number of people affected by noise around an airport depends on the way in which the land inside NPZ is used, there is a need to take into account interests of both sides: on one hand - airport operation mode and future development, and on the other hand - control of noise sensitive activities of community living in the vicinity of an airport.

\section{Iasi Airport (Romania)}

Iasi International Airport is located approximately $4 \mathrm{~km}$ from Iasi city, in the North-Eastern part of Romania. The airport has three main domestic routes (Bucharest, Cluj-Napoca and Timisoara), as well as various international routes towards over 15 countries, within and outside the European Union. All regular/charter flights are operated on a single runway and in partnership with eight airlines. The importance of the airport at a regional level is emphasized through its location, offering its services to a population of almost four million people, spread across $37,000 \mathrm{~km}^{2}$. Botosani, Suceava, Neamt, Bacau, Vaslui and Iasi are the main counties serviced by the airport and its operations are also used by many citizens from the Republic of Moldova.

Prior to the effects of COVID-19 on air traffic operations, Iasi Airport was classified among fastgrowing airports in Europe. Even in the beginning of 2021, in spite of all challenges faced by airports at a global level, this airport remained among the busiest five Romanian Airports in terms of aircraft movements.

The rationale behind this case study was derived from the fact that Iasi Airport started to face encroachment issues in the absence of effective legislative LUP provisions. Noise zoning around airports and preventive/ corrective actions against encroachment were limited to few and unclear recommendations and also spread across different legislations in an unharmonized manner. Thus, the airport took the initiative, with the support of INCD-T COMOTI, in raising awareness about this issue, which has become common to almost all Romanian airports.

\section{Method}

In order to raise awareness about the pressure of encroachment on airport operations and its corresponding noise effects on neighboring communities, the airport launched a workshop regarding LUP in 2018, to engage as many stakeholders as possible. With the support of the ANIMA project and many of its consortium partners, the airport managed to initiate discussions with representatives from the Civil Aviation Authority (CAA), the Ministry of Environment, airlines operating in Romania, the Association of Airports from Romania, other aviation stakeholders (e.g. airspace procedure designers), independent experts (aviation, environment), as well as with members from communities around the airport. The aim of this meeting was to develop a common understanding of the issue, while gathering input from as many stakeholders as possible with regards to future steps towards finding effective solutions. The main conclusion was that aircraft noise has become a pressing problem and that it should be managed appropriately through the use of all available tools (e.g. ICAO Balanced Approach pillars).

After the 2018 workshop, continuous communication between most stakeholders (workshop participants) was ensured through individual periodic meetings and responsibilities started to be shared among them accordingly in order to make use of available tools for managing aircraft noise.

Apart from having defined a clear need to tackle encroachment at a national level, identified 'best practice' from other airports (e.g. Kiev Airport, Heathrow Airport) has contributed significantly to formulate the strategy of this intervention in order to support the definition of LUP provisions in a clear and transparent manner. In this sense, all relevant policy-makers were identified (Ministries of Environment, Transport, and Regional Development and Tourism). After an extensive analysis of the available legislative framework, various gaps and unclarities were identified: unclear responsibilities regarding noise restrictions for residential buildings near airports, absent aircraft noise limits that influence the possibility to undergo constructions around airports, unclear procedures to follow during constructions performed around airports related to aircraft noise and absent corrective actions against failure to account for aircraft noise during residential development projects. Each party was invited to open discussions in order to investigate their individual responsibility for managing noise and their limitations to support the implementation of LUP provisions in Romania. The identification 
of various gaps regarding the general management of air traffic noise led to the conclusion that LUP could not be effectively regulated without a strong, clear, transparent and harmonized national legislation, which determined the need for the airport to offer permanent support to all stakeholders in investigating all missing links and limitations (e.g. only the airport was responsible for air traffic noise management). Continuous communication (face-to-face meetings, e-mails, phone discussions) with stakeholders has led to clarifications within the present noise legislation, as well as to additions enforcing its application (e.g. extension of responsibilities among all stakeholders) and has supported the development of the LUP basis in Romania, within the Air Code.

\section{Results}

Responsibilities of each stakeholder were further included as mandatory provisions within the legislation. The ANSP included Noise Abatement Departure Procedures (NADPs), the Ministry of Environment has drafted a new Noise Law and the Ministry of Transport, together with the support of the CAA, has worked on drafting a new version of the Air Code that includes mandatory noise zoning provisions. Even after so many efforts concentrated in the past few years, LUP provisions are still at an incipient phase. Next steps include the definition of methodologies for developing noise maps, for noise zoning and for establishing noise protection zones.

\section{Lessons learned}

Best practice examples from other airports could serve as a good initial informative basis for understanding the options to approach LUP interventions. In spite of this, such information is always limited in application to the local context (e.g. legislation, costs, available personnel). In the case of Romania, LUP measures can be implemented only by Local Public Administration Authorities. Therefore, the available options of Romanian airports to act upon such issues are limited and restricted by law. However, raising awareness about encroachment and supporting the policy-makers in preparing a resolution in this sense has the potential to become an effective initiative of airports in tackling such issues, through constant communication, to protect both citizens and airport expansions while preventing future noise operating restrictions and supporting regional economic growth.

Continuous communication among relevant stakeholders for aircraft noise management had a significant contribution to achieving a harmonized legislative framework in this sense. Therefore, all provisions across legislations and initiatives (e.g. NADPs) are interconnected and have a clear dependency between each other and serve as a clear foundation for a further adoption of effective LUP provisions. For example, the noise zoning process (from the Air Code) is required to be based on noise maps (from the Noise Law) for all Romanian airports and the noise protection zones determined through this process have to be integrated within the wider LUP spectrum in the region, i.e. in Urbanism Plans (from the General Regulation on Urbanism).

\subsection{Interdependencies between noise and emissions}

Interdependencies between noise and emissions were studied at Cluj airport (Romania).

\section{Cluj “Avram Iancu” Airport (Romania)}

Cluj International Airport is located in the proximity of Cluj-Napoca city in Romania. This airport is the second busiest airport in the country, with approximately 3 million passengers in 2019.

This intervention was initiated by Cluj Airport and was performed with the support of INCD-T COMOTI and an airline. The study aimed at understanding the challenges of interdependencies between noise and emissions and was performed through the use of airline data. The rationale behind this initiative was that noise, emissions and air quality are the main environmental concerns in rapidly growing airports and an understanding of their relationship could support the identification of appropriate solutions to balance them.

\section{Method}

In order to initiate this study, 'best practice' examples (e.g. Catania Airport) and a brief bibliographic review was performed in this sense. Further, an airline with regular flights on Cluj Airport was selected. One key aspect in the selection of procedures to be analyzed was the use of NADPs (Noise Abatement Departure Procedures) - NADP1 and NADP2. Through the use of both types of 
procedures, it was already known that fuel consumption rates differ from one procedure to another. Even so, an understanding related to real noise variation, as well as regarding differences in terms of emissions and air quality were missing. Therefore, an investigation of this gap was launched to understand the role of interdependencies within an airport context, through the use of airline data. The data analysis aimed to demonstrate if the initial purpose of using NADPs (i.e. reducing noise and emissions) will be confirmed.

Data from the Aeronautical Information Publication about the use of NADPs and input airline data (flight data sets from February and July, 2020) were used. The information included runway requirements for using NADPs, flight phase, flight level, latitude, longitude and fuel consumption for the same aircraft type, engine and maximum take-off weight (MTOW). The data set was reduced to a total of ten NADP procedures.

Through the use of simulation tools, a GIS (Geographic Information System) map was developed and the population was distributed uniformly (due to unavailable precise data). Noise contours were computed using the $\mathrm{L}_{\text {day }}$ indicator, for five NADP1 and five NADP2 procedures. An analysis in terms of number of people exposed to different levels of noise was also performed.

Fuel consumption data was used for the investigation of the quantity of emissions produced from both NADPs. Further analyses were performed to determine the $\mathrm{CO}$ (carbon monoxide) and $\mathrm{NO}_{\mathrm{X}}$ (nitrogen oxides) emission (at the level of residents from Cluj-Napoca city) and dispersion of pollution (at the level of the airport). $\mathrm{CO}$ and $\mathrm{NO}_{\mathrm{X}}$ exposure of the population to different particle concentrations was additionally derived.

\section{Results}

From the noise exposure analysis, it resulted that NADP2 exposed more people to higher levels of noise, while NADP1 exposed more people to lower levels of noise.

The fuel consumption data analysis showed that the quantity of $\mathrm{CO}_{2}$ emission up to 3,000 $\mathrm{ft}$ was higher in the case of NADP1 than in the case of NADP2, validating the initial assumption of the airline, which preferred NADP2 over NADP1 for decreased fuel consumption values. However, $\mathrm{NO}_{\mathrm{X}}$ and $\mathrm{CO}$ values were higher during the use of NADP2 in comparison to NADP1. Results from the study related to the exposure of the population to $\mathrm{CO}$ and $\mathrm{NO}$ x showed that NADP2 exposes more people to higher particle concentrations than it is the case of NADP1.

\section{Lessons learned}

In order to achieve a better understanding of the interdependencies problem and to investigate efficient trade-off options between noise, emissions and air quality, more research is needed to account for additional criteria (e.g. meteorological conditions, different MTOWs, airport and local community configuration, different NADP initiation points etc.).

Additional variables may also influence the implementation of effective trade-off strategies, such as the availability of training for air traffic controllers and pilots to use such procedures, aircraft performance characteristics, incompatible LUP (influencing an increase in the number of people exposed in certain areas, in comparison to others).

To facilitate a better understanding of this issue, a broader set of flight data is necessary. In this case, the impact of COVID-19 on available data has reduced the data set significantly.

\section{DISCUSSION AND CONCLUSIONS}

This paper presented the approaches and outcomes of six exemplification case studies conducted at airports throughout Europe, aiming to address challenges related to noise management at airports, guided by the ICAO Balanced Approach [6] and previously identified best practices.

Results from case studies on communication and community engagement reaffirm the importance of sharing information and addressing dilemmas to create understanding, empathy and trust among the wide variety of stakeholders that influence or are affected by aircraft noise around airports. Information shared and discussed should not only describe changes (often of a rather technical nature), but also pay attention to the implications and impacts of such changes for stakeholders. Especially for communities and non-experts, materials should be simple (without oversimplifying), 
such that affected stakeholders truly understand how their situation might change. Dedicated workshops or a (continuous) dialogue forum were found to be valuable methods to exchange information and views. Outcomes of case studies at Heathrow and Rotterdam The Hague airports, which wrestle with the implications of changing the distribution of noise (e.g. concentrating or dispersing flights, or moving a departure route), indicated a general preference for sharing noise impacts across the community, rather than optimizing the situation for some at the cost of others. The fact that this outcome was found for airports of notably different sizes suggests it might be a preference shared more widely.

The two case studies focused on land-use planning in different stages of development highlight the relevance of balancing interests: airport operation and development on one hand, and regional development and protecting communities in the airport vicinity from noise impacts on the other. Also in these case studies, the importance of communication, engagement and dialogue was evident. In the Iasi Airport (Romania) case study, collaborating openly with a variety of stakeholders (while recognizing individual responsibilities and limitations) proved helpful in designing an effective legislative land-use planning framework.

A final case study on interdependencies between noise and emissions at Cluj Airport (Romania) found that NADP1 procedures can expose more people to lower levels of noise than NADP2, while at the same time increasing aircraft fuel consumption and $\mathrm{CO}_{2}$ emission below 3,000 ft. Although interdependencies might not have received as much interest as land-use planning or flight procedure design yet, results from other case studies hint at the important role community engagement and broad stakeholder involvement can play in helping strike the balance between noise and emissions.

Regardless of the lessons learned from individual case studies documented in the previous section and the outcomes shared between (clusters of) case studies as just discussed, it is important that the design of an effective intervention takes the local characteristics (e.g. airport size and type, regional context, communication culture) into account. Lessons and best practices identified elsewhere (as collected on the ANIMA Noise Platform [17]) can be used as a starting point for an intervention design, but parties should be cautious in directly applying these to another situation. Pointed out specifically in the Iasi airport land-use planning case study, legislation and stakeholder responsibilities, for example, may vary. Moreover, it is emphasized that the outcomes presented here are case study results, in some cases based on limited participant samples and, due to COVID-19, conducted in an atypical situation (e.g. lower traffic levels) or setting (online events).

Besides evaluating various best practices across and beyond the ICAO BA, the case studies identify knowledge gaps and give rise to recommendations for future research. For example, information on the long-term health consequences of noise concentration or sharing is currently lacking. Given the fact that study results documented here do not align with the current EU policy focus (limiting the number of people significantly affected by aircraft noise, for example by concentrating flight paths), a larger study on public preferences might aid effective policy-making. Finally, the identification, collection and evaluation of guidelines or best practices for effective communication and community engagement to build mutual understanding and trust and to facilitate collaboration is put forward as key recommendation. As every one of the six case studies presented here shows, these topics play an undeniable role in managing the impacts of aviation noise, and therefore should receive at least as much attention as the themes currently included in the ICAO Balanced Approach.

\section{ACKNOWLEDGEMENTS}

This study was done as part of the Aviation Noise Impact Management through Novel Approaches (ANIMA) project. This project has received funding from the European Union's Horizon 2020 research and innovation programme under grant agreement No 769627. The authors thank participating airports for their cooperation.

\section{REFERENCES}

1. EEA, EASA \& EUROCONTROL. European Aviation Environmental Report 2019. (2019) 
2. EUROCONTROL. European aviation in 2040 - Challenges of Growth. (2018)

3. Sman, E.S. van der, Peerlings, B., Kos, J., Lieshout, R. \& Boonekamp, T. Destination 2050. Royal Netherlands Aerospace Centre, Amsterdam, The Netherlands (2021).

4. Aalmoes, R., Bartels, S., Benz, S., Großarth, S., Hauptvogel, D., Haubrich, J., Heyes, G., Hooper, P., Kotzinos, D., Kuhlmann, J., Müller, U., Richard, I., Lavandier, C., Ohlenforst, B., Roosien, R., Marki, F., Quehl, J. \& Schreckenberg, D. Reducing noise impact and improving quality of life by addressing annoyance. Forum Acusticum, December 2020.

5. Sustainable Aviation. Inter-dependencies between emissions of $\mathrm{CO}_{2}, \mathrm{NO}_{X} \&$ noise from aviation. (2017)

6. ICAO Doc. 9829, Guidance on the balanced approach to aircraft noise management. Second edition, 2008.

7. ICAO Working Paper A40-WP/260, Management of noise. 2019. https://www.icao.int/Meetings/A40/Documents/WP/wp_260_en.pdf

8. EUROCONTROL. Specification for Collaborative Environmental Management (CEM). Edition $1.1,2018$.

9. Heyes, G., Raje, F., Hooper, P., Hudson, R. \& Dimitriu, D. Critical Assessment of Aviation Noise Communication Strategies in the European Union. Proceedings of INTER-NOISE and 2019, pp. 4377-4388. Madrid, Spain, June 2019.

10. UK Government. Aviation 2050, The future of UK aviation - A consultation. London, United Kingdom (2018).

11. Department for Transport (2017). Air Navigation Guidance 2017. London, United Kindom (2017). https://assets.publishing.service.gov.uk/government/uploads/system/uploads/ attachment_data/file/918507/air-navigation-guidance-2017.pdf

12. Civil Aviation Authority. CAP 1616: Airspace Change. Guidance on the regulatory process for changing the notified airspace design and planned and permanent redistribution of air traffic, and on providing airspace information. West Sussex, United Kingdom (2021).

13. Civil Aviation Authority. CAP 1378: Performance-based Navigation Airspace Design Guidance: Noise mitigation considerations when designing PBN departure and arrival procedures. West Sussex, United Kingdom (2016).

14. Ganić , E., Oosten, N. van, Meliveo, L., Jeram, S., Louf, T. \& Ramasco, J. J. Dynamic noise maps for Ljubljana airport. SESAR, Brussels (2020). https://www.sesarju.eu/sites/default/files/ documents/sid/2020/papers/SIDs_2020_paper_81\%20final\%20version.pdf

15. ANIMA. Transparent noise management and community engagement in the Ljubljana Airport area. Kranj, Slovenia (2019). https://animaproject.eu/fileadmin/user_upload/ANIMA_Kranj_Web_version.pdf

16. Decree on limit values for environmental noise indicators. [Uredba o mejnih vrednostih kazalcev hrupa v okolju (Uradni list RS, št. 43/18 in 59/19)] (2019). http://www.pisrs.si/Pis.web/pregledPredpisa?id=URED7531

17. ANIMA. Noise platform. (2021). https://anima-project.eu/noise-platform/main-page 